\title{
The role of habenular nuclei in the selection of behavioral strategies
}

\author{
E. W. THORNTON and J. C. EVANS \\ University of Liverpool, Liverpool, England
}

\begin{abstract}
Bilateral lesions of the habenular nuclei in male Wistar rats were found to affect the selection of motor activities under stress. Specifically, in the absence of an available escape strategy during a forced swimming test, animals with habenular lesions demonstrated fewer categories of intrinsically generated motor activities and fewer changes of strategy. In addition, when given the opportunity to escape, such animals seemed unable to utilize the extrinsic cue provided. These changes in behavior did not seem to be related to any gross alteration of motor and postural capacities or to a general decrease in motor activity and exploratory tendencies. It is suggested that the habenula is critically involved in the relay and integration of information from limbic structures and the striatum and that a component of the changed behavior may be a result of disruption in dopaminergic function.
\end{abstract}

Although considerable evidence describes the neural mechanisms involved in both "motivational" processes and the control of movement, little is known about how the limbic processes involved in the former gain access to action and the motor system (Mogenson, Jones, \& Yim, 1980). Few structures are well placed to serve such a function, and, although the nucleus accumbens has been implicated as a likely key structure (Graybiel, 1976), recent anatomical studies suggest that the habenular nuclei might equally be implicated in such integration.

The habenula is an atypical nucleus of the epithalamus, having no prominent ascending projections but outputs projecting caudally via the fasciculus retroflexus to the paramedian midbrain region with major terminals in the ventral tegmental area, subtantia nigra, and the median and dorsal raphe nuclei (Wang \& Aghajanian, 1977). There are reciprocal connections to the habenula from these structures together with afferents from limbic areas via the stria medullaris, and from the neostriatum via connections in the entopenduncular nucleus (Herkenhan \& Nauta, 1977; Pasquier, Anderson, Forbes, \& Morgane, 1977). This anatomical evidence not only supports an early suggestion of Nauta's (1958) for a pivotal role of the habenula within a dorsal pathway between limbic structures and the midbrain, but also extends it to suggest an impressive convergence of projections on the habenula from both the limbic system and the corpus striatum (Phillipson \& Griffith, 1980). There is, however, little behavioral and functional evidence as yet for any role of the nucleus in such integration.

The author's mailing address is: Department of Psychology, University of Liverpool, Liverpool L69 3BX, England.
The importance of the basal ganglia in movement is well documented, with support for a primary role in the temporal patterning of both complex learned motor responses and spontaneous behavior (Cools, 1980; Cools \& Van den Bercken, 1977; Wilburn \& Kesner, 1974). Cools (1980) has demonstrated that, under stress, manipulation of striatal dopamine systems affects the procedure for selecting an optimal behavioral strategy by changing the ability to switch intrinsically generated motor programs. Alterations in striatal function had little effect on the ability of animals to change response strategies in the presence of salient or relevant environmental stimuli.

The diversity of effects of limbic manipulation on behavior preclude simple functions. Nevertheless, there is considerable evidence to support an inability to suppress ongoing behavior with inflexibility to changing environmental demands following lesions in several areas (Gray, Davis, Feldon, Nicholas, Rawlins, \& Owen, 1981; Kolb, 1977; Oades, 1981). Given evidence for the convergence of outputs controlling both the suppression and selection of behavior on the habenula, the present study determined whether lesions of the nuclei would affect the selection of response strategies of animals under stress in both the presence and absence of a salient extrinsic stimulus.

\section{METHODS}

\section{Subjects}

Twenty-four male Wistar rats, derived from the colony maintained in the Department of Psychology, University of Liverpool, and weighing $543.6 \pm 36 \mathrm{~g}$, were housed individually at $70^{\circ} \pm 2^{\circ} \mathrm{F}$ in a 12-h light/dark cycle. Food and water were available ad lib.

Bilateral lesions were made in the habenula in 12 (experimental) animals. The coordinates were taken from the Pellegrino and 
Cushman (1967) atlas: $\mathrm{A}-\mathrm{P}=3.8, \mathrm{Lat}= \pm .7, \mathrm{H}=.7$. Animals were anesthetized with Nembutal ( $50 \mathrm{mg} / \mathrm{kg}$,ip), and an insulated stainless steel electrode with tip exposure of $.4 \mathrm{~mm}$ was inserted stereotaxically into the nuclei and the lesion made by passage of RF current of $7 \mathrm{~mA}$ for $12 \mathrm{sec}$ from a Grass Model LM4 lesion maker. Remaining (control) animals underwent sham operative procedures.

\section{Behavioral Observations}

All animals were tested 7 days after operative procedures on 4 successive days between 1000 and $1500 \mathrm{~h}$ during the light phase of the cycle. Observations were made by one experimenter and recorded on audiotape for subsequent analysis.

Day 1: Motor coordination. The animals were transferred individually to a larger novel cage $(140 \times 90 \times 50 \mathrm{~cm})$ and observed over a period of $5 \mathrm{~min}$ to check for the presence or absence of behavior characteristic of a normal rat and to check any putative morphological shortcoming in their behavior. The shortcomings looked for were: abnormal abduction or adduction of limbs, tongue protrusions, blepharoptosis and torticollis, uncoordinated movements of head, body, legs, or tail, and uncoordinated movement patterns. In addition, the presence or absence of the following behavior categories were noted: lying down, locomotion, sniffing, rearing, scanning, grooming, genital grooming, licking movements, and scrabbling at the floor.

Days 2 and 3: Open-field behavior. A holeboard enclosure similar to that first described by Boissier and Simon (1962) was used to test exploratory behavior. A square enclosure with walls $80 \mathrm{~cm}$ long and $80 \mathrm{~cm}$ high was used. The floor area was divided into nine equal squares with holes of $4.0-\mathrm{cm}$ diameter in each of the corner squares. Three centimeters below each hole were placed varied objects (rubber bung, brass rod, matches, and rolled piece of cloth). The enclosure was illuminated by a $60-\mathrm{W}$ lamp suspended $140 \mathrm{~cm}$ above the center of the floor.

Each animal was placed individually in the apparatus at the same position, and behavior was recorded over a 6-min test. General activity was related to rearing, number of squares entered, and the duration of time spent freezing (absence of movement). Hole exploration was scored for both frequency and duration of head dipping, with scores related to a criterion of both eyes' disappearing into the hole. To keep odors to a minimum, the floor and holes were cleaned after each animal had been tested.

Day 4: Swimming test with and without escape. The procedures used for the swimming test were similar to those reported by Cools (1980). A cylindrical glass tank of $30-\mathrm{cm}$ diameter and $45-\mathrm{cm}$ height was filled with warm water $\left(30^{\circ} \pm 2^{\circ} \mathrm{C}\right)$ to a depth of $35 \mathrm{~cm}$.

Table 1

Categories of Behaviors Discriminated During the Swimming Test

Experimental Control

Animals Animals

Environmentally Oriented Behaviors (EOB)

(a) swimming to the side of the cylinder and "exploring" the side just above the surface of the water with snout and forelimbs

(b) diving to the bottom of the tank and "exploring" under water

(c) crossing the center of the tank and treading water with scanning of the area above the water

Total EOB categories
Total number of repetitions of categories
Total Duration (seconds) of EOBs $\begin{array}{cc}1.08 \pm 0.3 & 2.08 \pm 0.8 \\ 2.08 \pm 2.3 & 6.6 \pm 4.4 \\ 103 \pm 29 & 138 \pm 49\end{array}$

Drowning-Like Behavior

Rats sink down to the bottom of the tank and then actively swim back up

Life-Saving Behaviors (LSB)

(a) swimming along the side of the tank

(b) swimming in circles

(c) treading water in center of tank

(d) treading water and using forelimbs to keep contact with the sides of the tank

(e) "planing" without success: Rats attempting to float passively on surface of the water

(f) crossing the center

(g) sinking below the surface for about 1 sec during treading water around the edge of the tank

Total LSB categories

Total number of repetitions of categories

$1.9 \pm 1.5 \quad 3.7 \pm 0.8$

$5.3 \pm 6.7 \quad 12.4 \pm 4.5$

\section{Escape Behavior}

(a) escape with all limbs above the surface of the water

(b) attempted escape in which animal climbed on rope but failed to reach the criterion 
The test commenced by bringing the snout of the rat-which was held at the tail-to a distance $30 \mathrm{~cm}$ above the center of the water surface and dropping it into the tank. Behaviors were observed for $6 \mathrm{~min}$. During the first period, "environmentally oriented behaviors" (see Table 1 for description of behaviors) were qualitatively analyzed to determine whether animals, forced to swim in an unknown environment, were able to detect characteristic features of the available external stimuli and to organize their behavior accordingly. During the later phase of the test, "life-saving behaviors" (see Table 1) were performed, and these were analyzed to detect the sequential organization of behavior of animals forced to swim in the stable environment when there was no possibility of escape. Only factors inherent to the animal determined the initiation, maintenance, and termination of ongoing behavior.

Following the 6-min observation, a rope, $20 \mathrm{~cm}$ in length, $2 \mathrm{~cm}$ in diameter, and attached to a rigid piece of wood, was suspended vertically above the tank such that the bottom of the rope touched the midpoint of the water surface. Behaviors were observed in the presence of this salient extrinsic stimulus for a 2-min period or until the animal escaped from the tank via the rope. The criterion for escape was the full visibility of the hindlimbs above the water surface. In the absence of escape, animals were removed from the tank after the total 8 min of observation.

\section{RESULTS}

\section{General Behavior Repertoire}

During testing in the novel cage, all animals, to a greater or lesser extent, displayed all the categories of behavior described. All remained active throughout the 5 min of observation, and no animal showed any of the abnormal postures or movements described under Methods.

\section{Open-Field Exploration}

Results of observations in the holeboard test are presented in Table 2 . Both groups of animals showed exploratory behavior directed towards objects beneath the holes, although not all the animals in each group directed attention to all four holes. MannWhitney comparisons showed no significant differences between lesioned animals in either number (Trial 1, $U=70.5$; Trial 2, $U=43.5$ ) or duration (Trial 1, $U=59.5$; Trial 2, $U=48.5$ ) of head dips, and, therefore, there was no support for an effect of habenular lesions on this measure of exploratory behavior. Similar comparisons showed no significant effects of lesions on the number of squares entered (Trial 1, $U=59$; Trial 2, $U=46$ ) or the time spent immobile (Trial $1, U=61$; Trial $2, U=58.5$ ). There was, however, a significant difference between groups in number of rears, with lesioned animals showing reduced rearing $(U=30, p<.02)$ on the first, but not the second $(U=64)$, test session.

\section{Swimming and Escape Behavior}

Categories of behavior used in this test were differentiated into environmentally oriented behaviors (EOB), life-saving behaviors (LSB), and escape behaviors (EB) and are described in Table 1. On entry into the water, all animals displayed one or more of the EOB. Only one experimental animal, however, performed more than one of the categories of EOB, while nine of the control animals performed at least two, with four displaying all three categories. This difference is significant $\left(\chi^{2}=8.4 \mathrm{p}<.02\right)$. Furthermore, there were more repetitions of strategy for control animals, with a resultant significant difference (Student $t$ test, $t=3.1, p<.02$ ) between groups in the mean number of changes of strategy prior to LSB.

Experimental animals changed to LSB at a significantly earlier time (Student $t=2.58, p<.05$ ) and performed, relative to controls, significantly fewer different categories of LSB. As with EOB, there was a significant difference between the mean number of strategy changes of LSB for lesioned (mean $=5.3$ ) and control $($ mean $=12.4)$ animals (Student $t=2.94$, $\mathrm{p}<.02)$. In addition, only animals from the control group showed evidence of "drowning-like behavior," in which rats sink to the bottom of the tank before swimming back to the surface. Although "planing without success" was seen more frequently in control animals, no animal maintained such behavior, characterized as "helplessness" (Porsolt, Anton, Blauet, \& Jalfre, 1978), for more than $16 \mathrm{sec}$.

Table 2

Means and Standard Deviations of the Behaviors Observed in the Holeboard Test on 2 Consecutive Days of Observation for Both Habenular Lesioned Animals and Sham-Operative Controls

\begin{tabular}{|c|c|c|c|c|c|c|c|c|c|c|c|c|}
\hline & & & & & \multicolumn{8}{|c|}{ Activity Measures } \\
\hline & \multicolumn{4}{|c|}{ Exploratory Measures } & \multirow{2}{*}{\multicolumn{2}{|c|}{$\begin{array}{c}\text { Number of } \\
\text { Visits to } \\
\text { Outside Squares } \\
\end{array}$}} & \multirow{2}{*}{\multicolumn{2}{|c|}{$\begin{array}{l}\text { Number of } \\
\text { Visits to } \\
\text { Inside Squares } \\
\end{array}$}} & \multirow{2}{*}{\multicolumn{2}{|c|}{$\begin{array}{l}\text { Number of } \\
\text { Rears }\end{array}$}} & \multirow{2}{*}{\multicolumn{2}{|c|}{$\begin{array}{l}\text { Duration of } \\
\text { Freezing }\end{array}$}} \\
\hline & \multicolumn{2}{|c|}{$\begin{array}{l}\text { Number of } \\
\text { Head Dips }\end{array}$} & \multicolumn{2}{|c|}{$\begin{array}{c}\text { Duration of } \\
\text { Head Dips }\end{array}$} & & & & & & & & \\
\hline & Mean & $\mathrm{SD}$ & Mean & SD & Mean & SD & Mean & SD & Mean & SD & Mean & SD \\
\hline & \multicolumn{12}{|c|}{ Trial 1} \\
\hline Habenular Lesion & 6.42 & 3.23 & 17.25 & 8.23 & 61.75 & 27.77 & 1.58 & 2.02 & 21.25 & 7.25 & 1.33 & 2.27 \\
\hline \multirow[t]{2}{*}{ Sham-Operative Control } & 6.33 & 2.64 & 20.92 & 10.14 & 58.80 & 13.65 & 1.16 & 1.47 & 28.08 & 4.67 & 2.00 & 3.07 \\
\hline & \multicolumn{12}{|c|}{ Trial 2} \\
\hline Habenular Lesion & 6.02 & 2.34 & 21.58 & 12.91 & 74.00 & 28.29 & 2.75 & 1.19 & 26.66 & 8.50 & .66 & 1.07 \\
\hline Sham-Operative Control & 7.92 & 3.50 & 15.17 & 5.02 & 58.83 & 19.16 & 1.33 & 1.37 & 26.83 & 7.92 & .25 & .86 \\
\hline
\end{tabular}

Note $-N=12$ for cach group; median number of fecal boluses $=0$ for each group. Durations are given in seconds. 
Changes in behavior, when the rope was suspended above the surface of the water, are presented in Figure 1. Most control animals reverted to exploratory behavior around the edge of the tank, although all touched the rope within $25 \mathrm{sec}$, with $75 \%$ escaping by $45 \mathrm{sec}$. Of the three animals failing to reach escape criterion, two made repeated attempts to climb up the rope without reaching the criterion, while the remaining animal resumed $\mathrm{LSB}$, having touched the rope only once. In contrast, only five experimental animals touched the rope, with one escaping and one attempting escape but failing to attain the criterion. The difference in behavior is statistically significant (Fisher probability test, $\mathrm{D}=1, \mathrm{p}<.01$ ).

On completion of the behavioral observations, brains were removed from the animals and histological examinations were made of frozen sections.

Lesion size was consistent with sections from all experimental animals, revealing destruction of both lateral and medial habenular nuclei with no invasion of the overlying hippocampal area and no extension into either dorsomedial or paraventricular thalamic nuclei. The extent of the largest and smallest lesion with a typical section is seen in Figure 2.

\section{DISCUSSION}

The reduced changes in behavior strategies in experimental animals during the initial $6 \mathrm{~min}$ of the swimming test confirm a role for the habenula in the selection of intrinsically determined motor acts. Although there was no stable asymptotic planing in controls, as has been reported in previous studies, of swimming without escape (Cools, 1980; Porsolt et al., 1978), the remaining categories of response were identical. The effects of the lesion are similar to those reported by Cools (1980) in the same test in normal rats treated with haloperidol or higher doses of apomorphine $(.1 \mathrm{mg} / \mathrm{kg})$, suggesting that these effects of habenular lesions may be a result of induced changes in dopaminergic function. This inference could be related to the direct connection from the basal ganglia or substantia nigra, the reciprocal dopaminergic connections from the ventral teg-

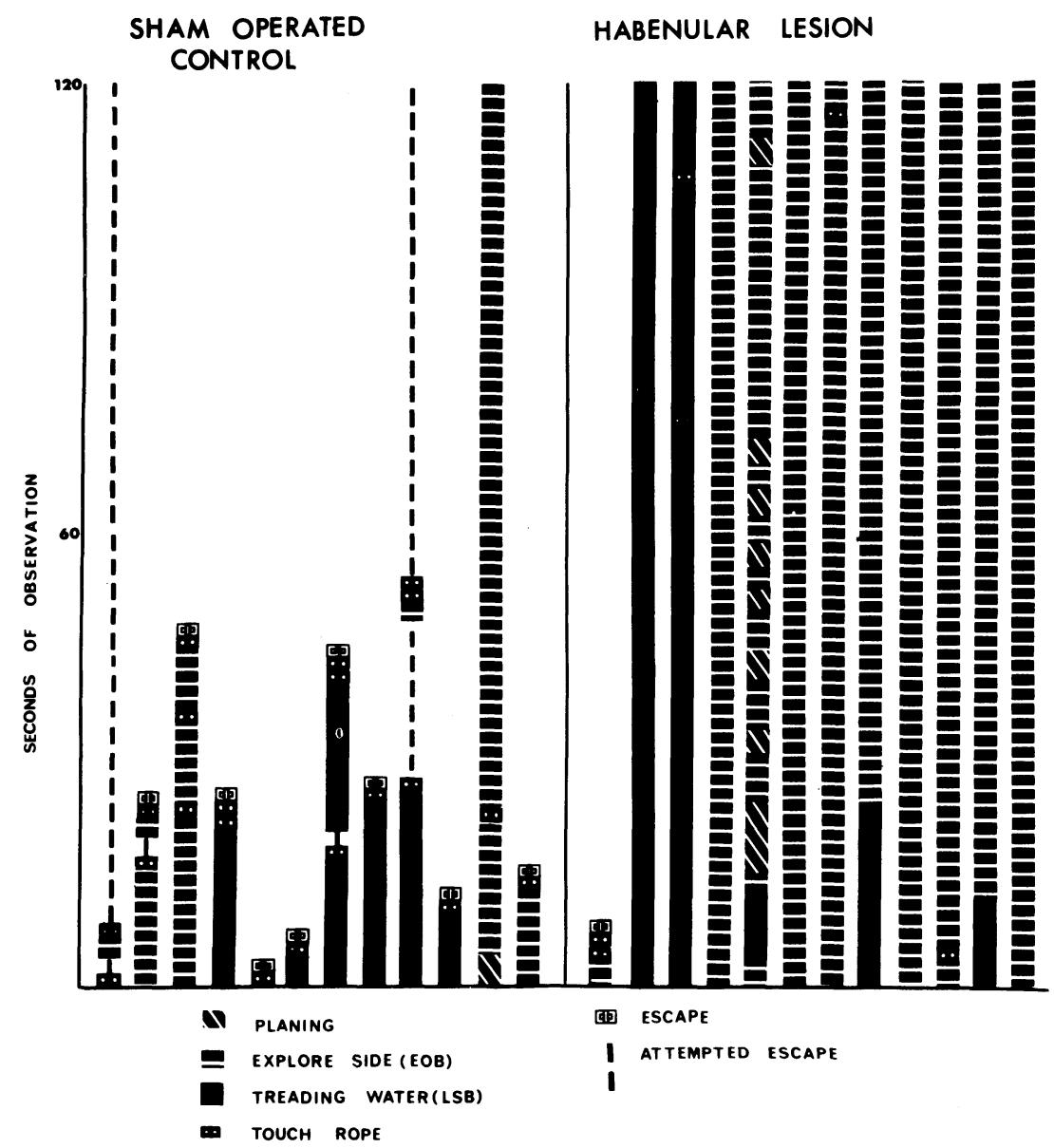

Figure 1. The profile of sequential changes in behavioral categories during the swimming test for both habenular lesion and control animals after the rope had been suspended in the tank. Each vertical extension represents changes in the behavior of one individual. 

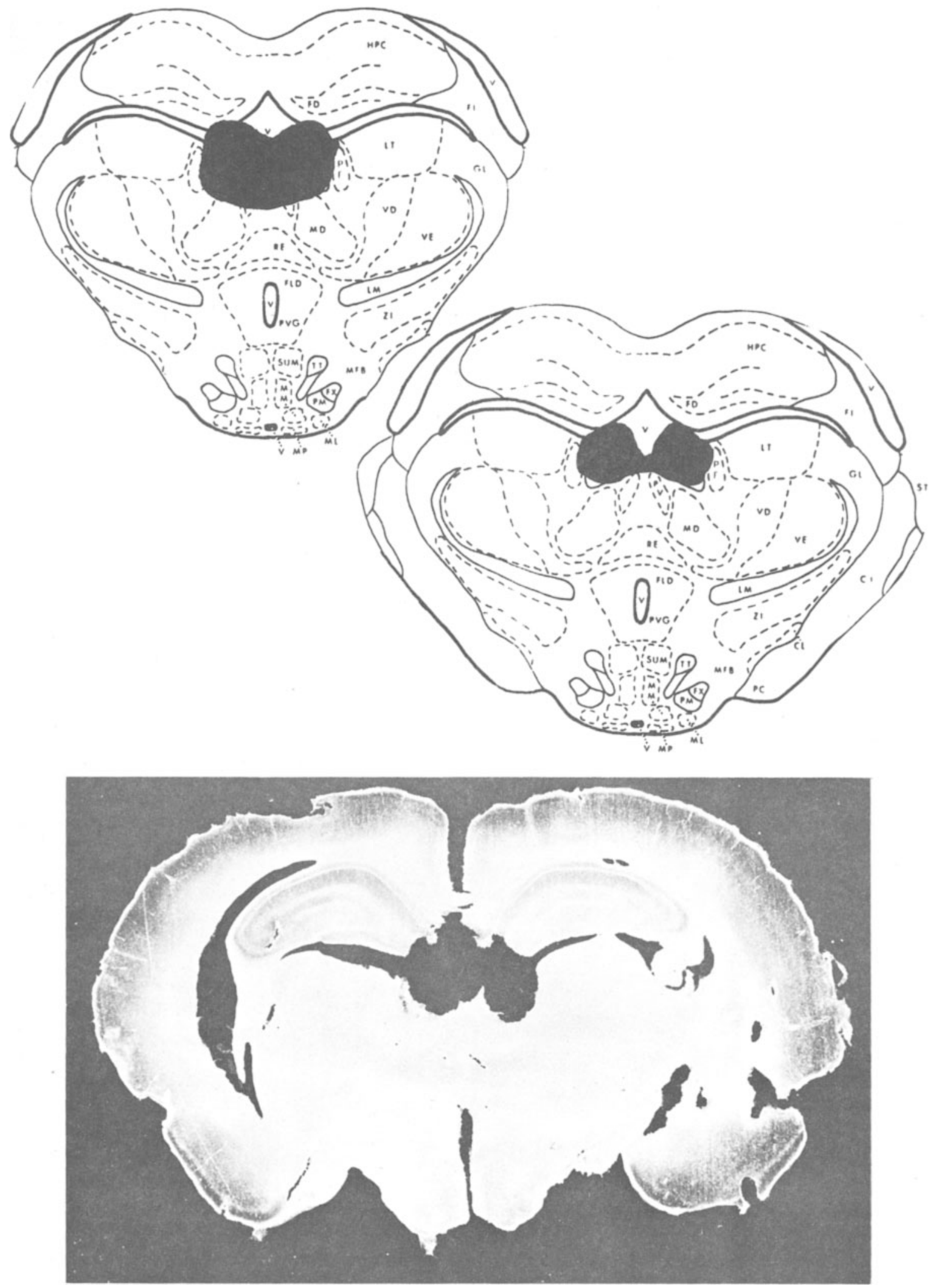

Figure 2. A representation of the extent of the largest and smallest lesions together with a representative section of a typical lesion. 
mental area (Phillipson \& Pycock, 1982), or the indirect pathway to the striatum via effects on the dorsal raphe nucleus (Vincent, Staines, McGeer, \& Fibiger, 1980).

The addition of the potential escape route in the form of the rope was used as a source of extrinsic information. Animals with habenular lesions were relatively poor at utilizing this information. This failure would not seem to be a consequence of a general change in exploratory behavior, since the holeboard test revealed no significant differences in either activity or hole exploration in experimental animals. If anything, animals with habenular lesions tended to greater activity. Observations, moreover, in the novel cage provided no evidence of any impairments of general motor function such that experimental animals would be less able to utilize the means of escape provided. This conclusion is supported by the successful rapid escape of the one experimental animal which did have more prolonged contact with the rope. The data show an attenuated response towards the rope in the experimental animals together with a significant reduction in the probability of escape or attempted escape for any contact with the rope. The deficit would, therefore, seem to be a consequence of a failure both to direct attention to the cue and to "realize" its significance. There is considerable evidence which supports a failure in attention and stimulus control following damage to limbic areas, particularly the septal (Donovick, Burright, Sikorszky, Stamato, \& Maclaughlin, 1978), hippocampal (Oades, in press; Rickert, Bennett, Lane, \& French, 1978), and frontal (Becker \& Olton, 1980; Nonneman, Voight, \& Kolb, 1974) areas. Damage in these areas results in an inability to suppress present behavior strategies in favor of those dictated by changed environmental events. Numan (1978) has specifically hypothesized a primary interaction in these structures for the formulation of "relevant" motor programs. The deficit in escape behavior in habenular animals suggests that such outputs may indeed be relayed through the habenula, as the anatomical evidence would suggest.

Given evidence for dopaminergic innervation of frontal cortical areas in the rat from the ventral tegmental area (VTA) (Emson \& Koob, 1978; Lindvall, Bjorklund, \& Divac, 1978), together with more specific evidence of the problems seen in effective programming of search strategies, following lesions of the VTA in the rat (Oades, 1982), a dopaminergic function would also seem relevant in the selection of response strategies in the presence of critical stimuli. The direct test of the hypothesis by Cools (1980), using dopamine agonists and antagonists, was interpreted in the negative although the data are ambiguous. However, the close parallel between the effects of haloperidol and habenular le- sions in the first part of the swimming test is not evident in the later part of the test when the rope was present, suggesting a nondopaminergic contribution to the deficit reported. Clearly, the specific neurochemical mechanisms involved in modulating differences in response strategy and those modulating the habenular effects reported here require more direct evaluation. The data do support the suggestion, nevertheless, that the outputs responsible for the selection of intrinsically and extrinsically determined strategies during stress are relayed or integrated through the habenular nuclei.

\section{REFERENCES}

Becker, J. T., \& Olton, D. S. Object discrimination by cats: The role of frontal and hippocampal systems in retention and reversal. Physiology \& Behavior, 1980, 24, 33-38.

Boissier, J. R., \& Simon, P. La réaction d'exploration chez la souris. Thérapie, 1962, 17, 1225-1232.

Cools, A. R. Role of the neostriatal dopaminergic activity in sequencing and selecting behavioral strategies: Facilitation of processes involved in selecting the best strategy in a stressful situation. Behavioral Brain Research, 1980, 1, 361-378.

Cools, A. R., \& VAN den Bercken, J. H. L. Cerebral organisation of behaviour and the neostriatal function. In A. R. Cools, A. H. M. Lohman, \& J. H. L. Van den Bercken (Eds.), Psychobiology of the striatum. Amsterdam: Elsevier/North Holland, 1977.

Donovick, P. J., Burright, R. G., Sikorszky, R. D., Stamato, N. J., \& Maclaughlin, W. W. Cue elimination effects on discrimination behavior of rats with septal lesions. Physiology \& Behavior, 1978, 20, 71-78.

Emson, P. C., \& Коов, G. F. The origin and distribution of dopamine-containing afferents to the rat frontal cortex. Brain Research, 1978, 142, 249-267.

Gray, J. A., Davis, N., Feldon, J., Nicholas, J., Rawlins, P., \& Owen, S. R. Animal models of anxiety. Progress in Neuropsychopharmacology, 1981, 5, 1-43.

Graybiel, A. M. Input-output anatomy of the basal ganglia. Proceedings of the Neurosciences Society, Toronto, Canada, 1976. (Abstract)

Herkenhan, M., \& Nauta, W. H. H. Afferent connections of the habenular nuclei in the rat. A horseradish peroxidase study with a note on fiber-of-passage problem. Journal of Comparative Neurology, 1977, 173, 123-146.

KoLB, B. Studies on the caudate-putamen and dorsomedial thalamic nucleus of the rat: Implications for mammalian frontallobe functions. Physiology \& Behavior, 1977, 18, 237-244.

Lindvall, O., Buorklund, A., \& Divac, I. Organization of catecholamine neurons projecting to the frontal cortex in the rat. Brain Research, 1978, 142, 1-24.

Mogenson, G. J., Jones, D. L., \& YIM, C. Y. From motivation to action: Functional interface between the limbic system and the motor system. Progress in Neurobiology, 1980, 14, 69-98.

NaUtA, W. J. H. Hippocampal projections and related neural pathways to the midbrain in the cat. Brain, 1958, 81, 319-340.

Nonneman, A. J., Voigt, J., \& KolB, B. E. Comparisons of behavioral effects of hippocampal and prefrontal cortex lesions in the rat. Journal of Comparative and Physiological Psychology, 1974, 87, 249-260.

Numan, R. Cortical-limbic mechanisms and response control: A theoretical review. Physiological Psychology, 1978, 6, 445-470.

OADES, R. D. Types of memory or attention? Impairments after lesions of the hippocampus and limbic ventral tegmentum. Brain Research Bulletin, 1981, 7, 221-226. 
OAdes, R. D. Search strategies on a holeboard are impaired in rats with ventral tegmental damage. Animal model for tests of thought disorder. Biological Psychiatry, 1982, 17, 243-258.

Pasquier, D. A., Anderson, C., Forbes, W. B., \& Morgane, P. J. Horseradish peroxidase tracing of the lateral habenula to midbrain raphe nuclei connections in the rat. Brain Research Bulletin, 1977, 1, 443-451.

Pellegrino, L. J., \& Cushman, A. J. A stereotaxic atlas of the rat brain. New York: Appleton-Century-Crofts, 1967.

Phillipson, O. T., \& Griffith, A. C. The neurons of origin of the mesohabenular dopamine pathway. Brain Research, 1980, 197, 213-218.

Phillipson, O. T., \& Pycock, C. J. Dopamine neurons of the ventral tegmentum project to both medial and lateral habenula. Some implications for habenular function. Experimental Brain Research, 1982, 45, 89-94.

Porsolt, R. D., Anton, G., Blauet, N., \& Jalfre, M. Behavioural despair in rats. A new model sensitive to antidepressant treatments. European Journal of Pharmacology, 1978, 47, 379-391.

Rickert, E. J., Bennett, T. L., Lane, P., \& French, J. Hippocampectomy and the attenuation of blocking. Behavioral Biology, 1978, 22, 147-160.

Vincent, S. R., Staines, W. A., McGeer, E. G., \& Fibiger, H. C. Transmitters contained in the efferents of the habenula. Brain Research, 1980, 195, 479-484.

Wang, R. J., \& Aghajanian, G. K. Physiological evidence for habenula as a major link between forebrain and midbrain raphe. Science, 1977, 197, 89-91.

Wilburn, M. W., \& Kesner, R. P. Effects of caudate nucleus stimulation upon initiation and performance of a complex motor task. Experimental Neurology, 1974, 45, 61-71.

(Manuscript received February 10, 1982; revision accepted for publication March 17,1982 .) 